\title{
Severe acute respiratory syndrome coronavirus nucleocapsid protein confers ability to efficiently produce virus-like particles when substituted for the human immunodeficiency virus nucleocapsid domain
}

\author{
Shui-Mei Wang $\cdot$ Yu-Fen Chang $\cdot$ Yi-Ming Arthur Chen • \\ Chin-Tien Wang
}

Received: 4 March 2008/ Accepted: 17 June 2008/Published online: 1 July 2008

(C) National Science Council Taipei 2008

\begin{abstract}
We replaced the HIV-1 nucleocapsid (NC) domain with different $\mathrm{N}$-coding sequences to test SARS$\mathrm{CoV}$ nucleocapsid (N) self-interaction capacity, and determined the capabilities of each chimera to direct viruslike particle (VLP) assembly. Analysis results indicate that the replacement of NC with the carboxyl-terminal half of the SARS-CoV N resulted in the production of wild type (wt)-level virus-like particles (VLPs) with the density of a wt HIV-1 particle. When co-expressed with SARS-CoV N, chimeras containing the $\mathrm{N}$ carboxyl-terminal half sequence efficiently packaged N. However, the same was not true for the chimera bearing the $\mathrm{N}$ amino-terminal half sequence, despite its production of substantial amounts of VLPs. According to further analysis, HIV-1 NC replacement with $\mathrm{N}$ residues 2-213, 215-421, or 234-421 resulted in efficient VLP production at levels comparable to that of $\mathrm{wt}$ HIV-1, but replacement with residues 215-359, 302-421, 2-168, or 2-86 failed to restore VLP production to wildtype levels. The results suggest that the domain conferring
\end{abstract}

S.-M. Wang - Y.-F. Chang

Institute of Public Health, National Yang-Ming University,

Taipei, Taiwan, ROC

S.-M. Wang · C.-T. Wang $(\varangle)$

Department of Medical Research and Education, Taipei Veterans

General Hospital, 201, Sec. 2, Shih-Pai Road, Taipei 11217,

Taiwan, ROC

e-mail: chintien@ym.edu.tw

Y.-F. Chang · C.-T. Wang

Institute of Clinical Medicine, National Yang-Ming University, Taipei, Taiwan, ROC

Y.-M. A. Chen

AIDS Prevention and Research Center, National Yang-Ming

University, Taipei, Taiwan, ROC the ability to direct VLP assembly and release in SARS$\mathrm{CoV} N$ is largely contained between residues 168 and 421 .

Keywords SARS-CoV N · HIV-1 NC ·

Virus-like particle assembly

\section{Introduction}

The novel infectious disease severe acute respiratory syndrome (SARS) [21] infected individuals in over 30 countries in 2002 and 2003 [50]. The causative agent was identified as the SARS coronavirus (SARS-CoV) [13, 21]. The complete SARS-CoV genome is approximately $30 \mathrm{~kb}$ long and contains 10-14 open reading frames [27, 36]. Like many other coronavirus species, the SARS-CoV is an enveloped virus containing three outer structural proteins: spike (S), membrane (M), and envelope (E) $[6,12,22,37]$. We know that nucleocapsid $(\mathrm{N})$ proteins associated with viral genomic RNA form a viral core within the envelope [29]; however, SARS-CoV assembly and budding processes are not completely understood. The co-expression of coronavirus $\mathrm{M}$ with $\mathrm{E}[2,17,44]$ or $\mathrm{N}[19,35]$ is sufficient for particle formation. According to these findings, the co-expression of at least two coronavirus structural proteins is required for virus-like particle (VLP) formation. In contrast, retrovirus assembly with polyprotein precursor gag gene expression is sufficient for producing VLPs [14].

Retroviral gag apparently possesses all required signals for VLP assembly and budding, and functional domains involved in coronavirus VLP assembly and budding are allocated throughout the $\mathrm{M}, \mathrm{E}$, and $\mathrm{N}$ proteins. Despite being completely unrelated, the SARS-CoV N protein and HIV-1 NC have similar properties: both contain putative proteinprotein interaction domains and both play roles in viral RNA 
packaging $[4,5,18,32,33,53]$. A domain responsible for Gag-Gag interactions (referred to as an I domain) has been mapped to HIV-1 NC [3, 7]. Likewise, recombinant SARS$\mathrm{CoV}$ nucleocapsid proteins can undergo multimerization via self-association [16, 30, 42, 51]. Since heterologous polypeptides that form interprotein contacts permit efficient VLP production when placed in the HIV-1 NC region [1, 9, 20, 54], we initially tested whether SARS-CoV N substitution for HIV-1 NC supports chimeric VLP assembly and release, and found that HIV-1 Gag mutants containing SARS-CoV N coding sequences as NC substitutes are capable of VLP assembly. This suggests that the HIV-1 NC assembly domain can be functionally replaced with the SARS-CoV N.

We employed this chimeric VLP assembly system to determine the boundaries of the SARS-CoV $\mathrm{N}$ coding sequence involved in conferring the ability to direct VLP assembly and release. Our results indicate that the carboxylterminal half of the SARS-CoV N protein functions in a manner similar to that of leucine zipper motifs in enabling efficient VLP production when substituted for HIV-1 NC.

\section{Materials and methods}

Plasmid construction

The parental HIV-1 proviral plasmid DNA used in this study was $\mathrm{HXB}_{2}$ [34]. The cDNA clone of the SARS-CoV $\mathrm{N}$ (SARS coronavirus strain TWC, GenBank accession number AY321118) was provided by the Centers for Disease Control of the Department of Health, Taiwan. A pair of upstream and downstream primers was used to amplify $\mathrm{N}$-coding fragments via PCR-based overlap extension mutagenesis [38]. Primers used to construct the CoN-myc encoding the SARS-CoV $\mathrm{N}$ tagged with Myc at the C-terminus were oligonucleotides 5'-GCGTGGATCCATG TCTGATAATGGACCC-3' (forward) and 5'-AGTGTGTC GACCTGAGTTGAATC- $3^{\prime}$ (reverse). The PCR-amplified fragment was digested with BamHI and SalI and ligated into pcDNA3.1/myc-His A (Invitrogen).

To construct GST fusions, amplicons containing SARS$\mathrm{CoV} \mathrm{N}$ coding sequences were digested with $\mathrm{BamHI}$ and $\mathrm{ClaI}$ and fused to the C-terminus of GST, which is directed by a mammalian elongation factor 1a promoter [11]. Primers for cloning GST fusions were GST-CoN, 5'-TAAAGGATCCTC TGATAATGGACCC-3' (forward), $5^{\prime}$-TCATATCGATTTAT GCCTGAGTTGAATC-3' (reverse); GST-N1, 5'-TAAAGGA TCCTCTGATAATGGACCC-3' (forward), 5'-GCTCATCG ATTAGCTAGCCATTCGAGC-3' (reverse); GST-N2, 5'-TG GCTGGATCCGGTGGTGAAACTGCC-3' (forward), 5'-TC ATATCGATTTATGCCTGAGTTGAATC- $3^{\prime}$ (reverse).

HIV-1 NC deletion mutants $\triangle \mathrm{NC}$ and $\triangle \mathrm{PC}$ were generated via recombinations of HIV gag mutants containing a BamHI linker inserted at nt 1907, 1918, 1940, or 2076. Recombinations of BamHI-2076 with BamHI-1940, BamHI-1907, and BamHI1918 , yielded constructs $\triangle \mathrm{NC}, \Delta \mathrm{PC}$ and delNC, respectively. Nucleotide sequences at breakpoints were: $\triangle N C$, nt 1935TTTAGGATCCAGGCT-2081, $\Delta$ PC, nt 1902-AATTCAGGGATCCAGGCT-2081, and delNC, nt 1912-CCATAAGG ATCCAGGCT-2081. To replace the HIV-1 NC with SARSCo N, SARS-CoV N cDNA fragments were PCR-amplified with $\mathrm{BamHI}-$ and/or ClaI-flanking primers. Amplicons were gel-purified, digested with $\mathrm{BamHI}$ and/or $\mathrm{ClaI}$, and ligated into $\triangle \mathrm{NC}$ and $\triangle \mathrm{PC}$ or into an HIV-1 gag mutant carrying ClaI and BamHI linker insertions at nt 1920 and 2076, respectively. Primers used for making the designated constructs were: $\triangle \mathrm{NC}(\mathrm{CoN})$ and $\mathrm{PC}(\mathrm{CoN}), 5^{\prime}$-TAAAGGATCCTCTCTGAT AATGGACC- $3^{\prime}$ (forward), 5'-TAAAGGATCCCCTGAGTT GAATCAGC- $3^{\prime}$ (reverse); $\triangle \mathrm{NC}(\mathrm{N} 2)$ and PC(N2), 5'-ATGC GGATCCTGCAGGGTGAAACTGCCCTCGC-3' (forward), 5'-TAAAGGATCCCCTGAGTTGAATCAGC-3' (reverse); $\mathrm{NC}(\mathrm{CoN}), \quad 5$-AGACATCGATCTGATAATGGACC- $3^{\prime}$ (forward), 5'-TAAAGGATCCCCTGAGTTGAATCAGC-3' (reverse); NC(N1), 5'-AGACATCGATCTGATAATGGAC C-3' (forward), 5'-TAAAGGATCCCCTGAGTTGAATCAG C-3' (reverse); NC(N2), 5'-GAATGGATCGATTAGGTGGT GAAACT- $3^{\prime}$ (forward), 5'-TAAAGGATCCCCTGAGTTGA ATCAGC-3' (reverse); NC(N3), 5'-GAATGGATCGATTAG GTGGTGAAACT-3' (forward), 5'-TGTTTGGATCCCGTC AATGTGCTTG-3' (reverse); NC(N4), 5'-AGACATCGATG CAAAGTTTCTGGTA-3' (forward), 5'-TAAAGGATCCCC TGAGTTGAATCAGC- $3^{\prime}$ (reverse); NC(N5), $5^{\prime}$-CGCAATC GATGGCCGCAAATTGCA- $3^{\prime}$ (forward), 5'-TAAAGGAT CCCCTGAGTTGAATCAGC-3' (reverse); NC(N6), 5'-AGA CATCGATCTGATAATGGACC-3' (forward), 5'-CCTTGG ATCCCTGTTGTTCCTTGAGG-3' (reverse); NC(N7), $5^{\prime}$-AG ACATCGATCTGATAATGGACC- $3^{\prime}$ (forward), 5'-GCTCA TCGATTAGCCAATTTGGTCAT-3' (reverse).

Plasmid DNAs containing wt (wtZiP) and mutant (KZiP) leucine zipper domains of human CREB [24] were kindly provided by E. Barklis [54]. cDNA fragments of the wt and mutant leucine zipper domains were PCR-amplified, digested, and ligated into $\triangle \mathrm{NC}$, yielding the respective constructs $\triangle \mathrm{NC}(\mathrm{wtZiP})$ and $\triangle \mathrm{NC}(\mathrm{KZiP})$. The myristylation-minus $\left(\mathrm{Myr}^{-}\right.$) HIV-1 gag mutant [45], (defective in membrane association) was used as a control for membrane binding assays. All of the engineered constructs were cloned into the PR-defective HIV-1 proviral expression vector HIVgptD25 [47]. Mutations were confirmed by restriction enzyme digestion or DNA sequencing.

Cell culture and transfection

The 293T cells were maintained in Dulbecco's modified Eagle's medium (DMEM) supplemented with $10 \%$ fetal calf serum (GIBCO). Confluent 293T cells were 
trypsinized and split $1: 10$ onto 10 -cm dishes $24 \mathrm{~h}$ prior to transfection. For each construct, cells were transfected with $20 \mu \mathrm{g}$ of plasmid DNA using the calcium phosphate precipitation method; $50 \mu \mathrm{m}$ chloroquine was added to enhance transfection efficiency. Unless otherwise indicated, $10 \mu \mathrm{g}$ of each plasmid was used for co-transfection. Culture supernatant and cells were harvested for protein analysis 2-3 days post-transfection.

\section{Western immunoblot}

At $48-72 \mathrm{~h}$ post-transfection, supernatant from transfected 293T cells was collected, filtered, and centrifuged through $2 \mathrm{ml}$ of $20 \%$ sucrose in TSE (10 mM Tris- $\mathrm{HCl}$ [pH 7.5], $100 \mathrm{mM} \mathrm{NaCl}, 1 \mathrm{mM}$ EDTA plus $0.1 \mathrm{mM}$ phenylmethylsulfonyl fluoride [PMSF]) at $4^{\circ} \mathrm{C}$ for $40 \mathrm{~min}$ at $274,000 \mathrm{~g}$. Pellets were suspended in IPB (20 mM Tris- $\mathrm{HCl}$ [pH 7.5], $150 \mathrm{mM} \mathrm{NaCl}, 1 \mathrm{mM}$ EDTA, $0.1 \%$ SDS, $0.5 \%$ sodium deoxycholate, $1 \%$ Triton $\mathrm{X}-100,0.02 \%$ sodium azide) plus $0.1 \mathrm{mM}$ PMSF. Next, cells were rinsed with ice-cold phosphate-buffered saline (PBS), collected in IPB plus $0.1 \mathrm{mM}$ PMSF, and microcentrifuged at $4^{\circ} \mathrm{C}$ for $15 \mathrm{~min}$ at $13,700 \mathrm{~g}$ to remove cell debris. Supernatant and cell samples were mixed with equal volumes of $2 \times$ sample buffer $(12.5 \mathrm{mM}$ Tris- $\mathrm{HCl}$ [pH 6.8], 2\% SDS, $20 \%$ glycerol, $0.25 \%$ bromphenol blue) and $5 \% \beta$-mercaptoethanol and boiled for $5 \mathrm{~min}$. Samples were resolved by electrophoresis on SDS-polyacrylamide gels and electroblotted onto nitrocellulose membranes. Membrane-bound Gag or chimeric proteins were immunodetected using a mouse monoclonal antibody directed against HIV-1 p24CA [46]. Myc-tagged SARS-CoV N were probed with anti-Myc (Invitrogen) monoclonal antibodies at a dilution of 1:5,000, respectively. The secondary antibody was a sheep antimouse or donkey anti-rabbit horseradish peroxidase-(HRP) conjugated antibody (Invitrogen) at 1:5,000 dilutions. To detect GST and GST fusions, anti-GST HRP conjugate (Amersham) was used at a 1:5,000 dilution. Horseradish peroxidase activity was detected according to the manufacturer's protocol.

\section{GST pull-down assay}

The 293T cells either mock transfected or transfected with GST fusion expression vectors were collected, lysed in RIPA buffer $\left(140 \mathrm{mM} \mathrm{NaCl}, 8 \mathrm{mM} \mathrm{Na} \mathrm{HPO}_{4}, 2 \mathrm{mM}\right.$ $\mathrm{NaH}_{2} \mathrm{PO}_{4}, 1 \% \mathrm{NP}-40,0.5 \%$ sodium deoxycholate, $0.05 \%$ SDS) containing complete protease inhibitor cocktail (Roche), and microcentrifuged at $4^{\circ} \mathrm{C}$ for $15 \mathrm{~min}$ at $13,700 \mathrm{~g}(14,000 \mathrm{rpm})$ to remove cell debris. Aliquots of post-nuclear supernatant (PNS) were mixed with equal amounts of $2 \times$ sample buffer and $5 \% \beta$-mercaptoethanol and held for Western blot analysis. RIPA buffer was added to the remaining PNS samples to final volumes of $500 \mu \mathrm{l}$. Each sample was mixed with glutathione agarose beads (30 $\mu \mathrm{l})\left(\right.$ Sigma) and rocked for $2 \mathrm{~h}$ at $4^{\circ} \mathrm{C}$. Bead-bound complexes were pelleted, washed tree times with RIPA buffer, twice with PBS, eluted at $1 \times$ sample buffer with $5 \% \beta$-mercaptoethanol, boiled for $5 \mathrm{~min}$, and subjected to SDS-10\% PAGE as described above.

Sucrose density gradient fractionation

Supernatant cultures of transfected 293T cells were collected, filtered, and centrifuged through $2 \mathrm{ml} 20 \%$ sucrose cushions as described above. Viral pellets were suspended in PBS buffer and laid on top of a pre-made 20-60\% sucrose gradient consisting of $1 \mathrm{ml}$ layers of $20 \%, 30 \%$, $40 \%, 50 \%$ and $60 \%$ sucrose in TSE that had been allowed to sit for $2 \mathrm{~h}$. Gradients were centrifuged in an SW50.1 rotor at $40,000 \mathrm{rpm}(274,000 \mathrm{~g})$ for $16 \mathrm{~h}$ at $4^{\circ} \mathrm{C} ; 500 \mu \mathrm{l}$ fractions were collected from top to bottom. Sucrose density was measured for each fraction. Proteins in each fraction were precipitated with $10 \%$ trichloroacetic acid (TCA) and subjected to Western immunoblotting.

\section{Membrane flotation experiments}

At $48 \mathrm{~h}$ post-transfection, 293T cells were rinsed twice, pelleted in PBS, and resuspended in TE buffer $(10 \mathrm{mM}$ Tris-HCl [pH 7.5], 1 mM EDTA) containing 10\% sucrose and complete protease inhibitor cocktail. Cell suspensions were subjected to sonication followed by low-speed centrifugation. About $200 \mu \mathrm{l}$ of post-nuclear supernatant (PNS) was mixed with $1.3 \mathrm{ml}$ of $85.5 \%$ sucrose in TE buffer, placed at the bottom of a centrifuge tube, and covered with a layer of $7 \mathrm{ml} 65 \%$ sucrose mixed with $3 \mathrm{ml}$ of $10 \%$ sucrose in TE buffer. Gradients were centrifuged at $100,000 \mathrm{~g}$ for $16-18 \mathrm{~h}$ at $4^{\circ} \mathrm{C}$. Ten fractions were collected from top-to-bottom of each tube. Proteins in each fraction were precipitated with ice-cold $10 \%$ trichloroacetic acid (TCA), rinsed once with acetone, and analyzed by Western immunoblot.

\section{Results}

Expression and assembly of chimeric proteins containing a SARS-CoV $\mathrm{N}$ coding sequence as a substitute for HIV-1 NC

For purposes of roughly defining the self-association involvement of the SARS-CoV nucleocapsid $(\mathrm{N})$ protein, we fused the complete length (GST-CoN), amino-terminal half (GST-N1), or carboxyl-terminal half (GST-N2) of the SARS-CoV $\mathrm{N}$ coding sequence to the GST carboxyl 
terminus; the expression of GST fusions was directed by a mammalian promoter (Fig. 1a). Each resulting construct was co-expressed with SARS-CoV N (CoN-myc) in 293T cells. GST pull-down assays were used to determine the ability of each GST fusion to interact with SARS-CoV N. Our results indicate that GST and GST-N1 were incapable of pulling down SARS-CoV N (Fig. 1b, lanes 6 and 8), while GST-CoN and GST-N2 were capable of doing so (lanes 7 and 9). This suggests that the domain responsible for $\mathrm{N}-\mathrm{N}$ interaction is largely contained within the carboxyl-terminal region-a finding compatible with those from previous reports [42, 43].

Next, we tested whether the self-interaction capacity of SARS-CoV $\mathrm{N}$ was sufficient for rescuing the assembly defect of HIV-1 NC-deleted mutants. Full-length or carboxyl-terminal halves of SARS-CoV were inserted in frames into the HIV-1 NC-deleted mutants $\triangle \mathrm{NC}, \triangle \mathrm{PC}$, and delNC (Fig. 2a), yielding chimeras $\Delta \mathrm{NC}(\mathrm{CoN}), \quad \Delta \mathrm{NC}(\mathrm{N} 2)$, $\mathrm{PC}(\mathrm{CoN}), \mathrm{PC}(\mathrm{N} 2), \mathrm{NC}(\mathrm{CoN})$, and $\mathrm{NC}(\mathrm{N} 2)$. The $\Delta \mathrm{NC}$ retained seven amino-terminal $\mathrm{NC}$ residues, and the $\triangle \mathrm{PC}$ associated deletions extended to four carboxyl-terminal SP1 residues. Two residues were removed from the SP1-NC junction of the delNC. Based on the possibility that the

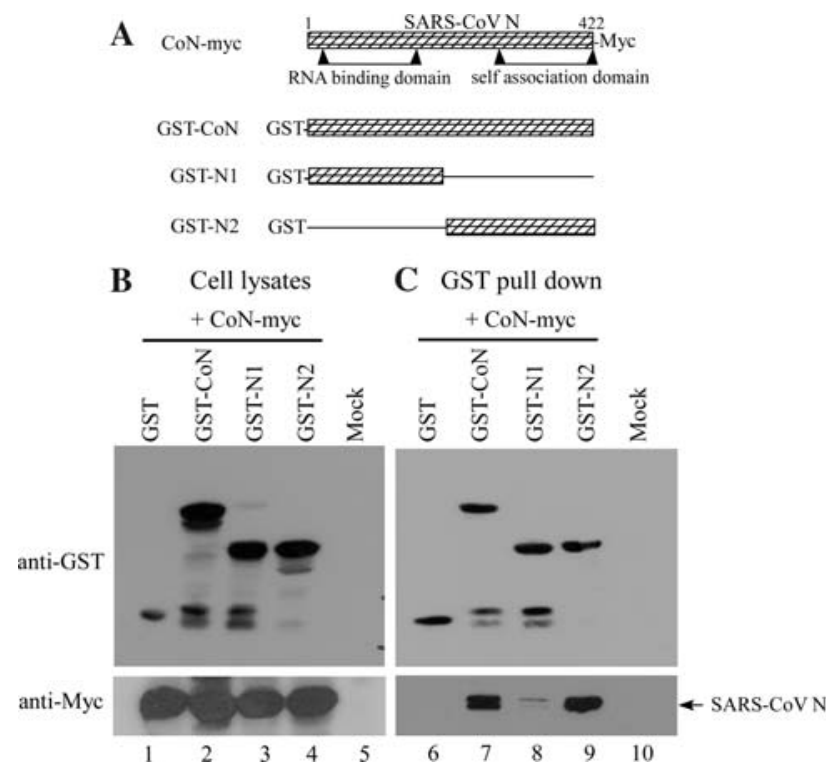

Fig. 1 SARS-CoV nucleocapsid protein self-association. (a) Schematic representations of construct coding for recombinant SARS-CoV $\mathrm{N}$ proteins. CoN-myc directed by a CMV promoter encoded fulllength SARS-CoV $\mathrm{N}$ tagged with $\mathrm{Myc}$ at carboxyl terminus. Boundaries of the RNA binding domain and self-association domain are indicated [41]. GST-CoN, GST-N1, and GST-N2 expressed GST fusion proteins with full-length, amino-terminal half, and carboxylterminal half of $\mathrm{N}$ fused to GST carboxyl terminus, respectively. (b, c) GST pull-down assay. 293T cells were co-transfected with $10 \mu \mathrm{g}$ of CoN-myc and $10 \mu \mathrm{g}$ of indicated GST fusion construct. Aliquots of cell lysates preceding (panel b) and following (panel c) GST pull-down were subjected to Western immunoblotting using anti-GST and anti-Myc antibodies as probes various NC mutations might impair VLP production to different degrees, we reasoned that the extent to which VLP assembly was restored following $\mathrm{N}$ sequence insertion might reveal the self-association capacity of each $\mathrm{N}$ sequence.

The backbone for all constructs was the PR-defective HIV-1 expression vector HIVgptD25, referred to in this study as a wild type (wt). Each mutant was transiently transfected into $293 \mathrm{~T}$ cells and subjected to Western immunoblotting to determine its ability to assemble and release VLPs. As shown in Fig. 2b, chimeric proteins with predicted molecular weights corresponding to $\operatorname{Pr} 55^{\text {gag }}$ containing a SARS-CoV $\mathrm{N}$ coding sequence insertion in the NC region were readily detected. Parental constructs with different extents of NC deletions were markedly defective in VLP production (Fig. 2b, lane 3 and Fig. 2c); in particular, the $\triangle \mathrm{PC}$ VLP assembly was almost abolished. Conversely, inserting the carboxyl-terminal half of SARSCoV $\mathrm{N}$ dramatically restored VLP production to wt level (Fig. 2b, lanes 7-9), suggesting that the carboxyl-terminal region of $\mathrm{N}$ that contains a putative self-association domain is capable of counteracting the assembly defect when placed in the HIV-1 NC region. Furthermore, we noted that $\triangle \mathrm{NC}(\mathrm{CoN})$ (with over 400 inserted amino acid residues) was still capable of directing VLP assembly and budding (Fig. 2b, lane 4). In contrast, $\mathrm{PC}(\mathrm{CoN})$ and $\mathrm{NC}(\mathrm{CoN})$ were moderately to markedly impaired in terms of VLP production (lanes 5 and 6$) . \triangle \mathrm{NC}(\mathrm{N} 2), \mathrm{PC}(\mathrm{N} 2)$ and $\mathrm{NC}(\mathrm{N} 2)$ possessed medium to cell $\mathrm{p} 24 \mathrm{CA}$-associated protein ratios that were even higher than the wt ratio. This result could be due either to increased assembly rate or to increased intracellular mutant degradation. A slight correlation was observed between level of VLPs produced by chimeras containing full-length $\mathrm{N}$ and the number of HIV-1 NC residues remaining in the deleted region. Since $\mathrm{NC}(\mathrm{CoN})$ has almost all of its $\mathrm{NC}$ removed but retains intact SP1-NC and NC-SP2 junctures, we used $\mathrm{NC}(\mathrm{CoN})$ or $\mathrm{NC}(\mathrm{N} 2)$ as models for studying the effects of inserted SARS-CoV $\mathrm{N}$ on VLP assembly.

Sucrose density gradient fractionation analysis of chimeric VLPs

The above results suggest that HIV-1 Gag containing a large sequence of approximately 200-400 residues inserted into the NC region is still capable of assembling and releasing VLPs. Since the cultured 293T transfectant supernatant was centrifuged through $20 \%$ sucrose cushions for $40 \mathrm{~min}$, we believe the recovered viral proteins in the pelleted medium are virus-associated. However, since the mutants contained large insertions, we performed sucrose density gradient fractionation experiments to determine whether the large insertion mutations had any effect on virus particle density. To make parallel comparisons with 


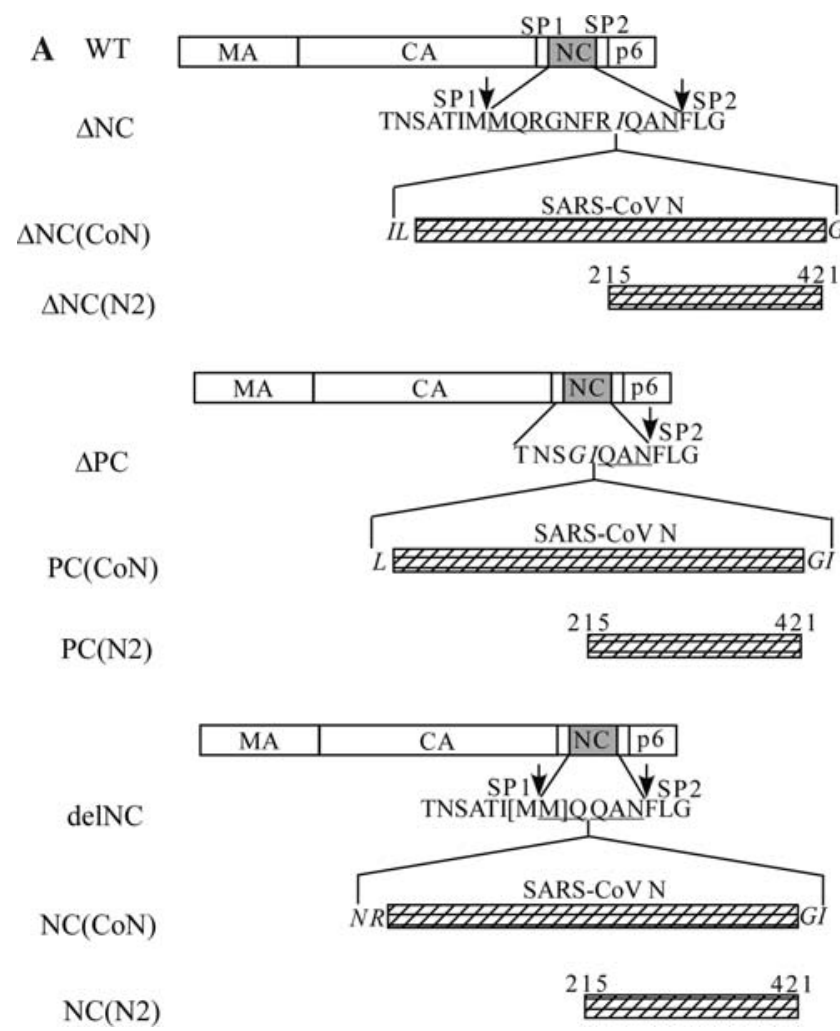

Fig. 2 Expression and assembly of chimeras containing SARS-CoV $\mathrm{N}$ coding sequences to serve as substitutes for the HIV-1 NC domain. (a) Schematic representations of wt HIV-1 Gag and mutant constructs. Shown are mature HIV-1 Gag protein domain matrix (MA), capsid (CA), nucleocapsid (NC), p6, and two spacer peptides (SP1 and SP2). $\triangle \mathrm{NC}$ has ten HIV-1 NC residues remaining in the deleted region; $\triangle \mathrm{PC}$ has $\mathrm{NC}$ almost deleted, with $\mathrm{SP} 1$ partially removed. delNC has the two methionine residues (bracketed) in the SP1-NC junction removed. Almost the entire (codons 2-421) or carboxyl-terminal half (215-421) of the SARS-CoV nucleocapsid protein $(\mathrm{N})$ coding sequence was inserted into the deleted $\mathrm{NC}$ region, yielding the designated constructs. Arrows indicate SP1-NC and NCSP2 junction sites. Remaining HIV-1 NC residues in deleted regions are underlined. Altered or foreign amino acid residues inserted in juncture area are italicized. Backbone was the protease-defective $\left(\mathrm{PR}^{-}\right)$expression vector HIVgptD25. (b, c) Expression and assembly

wt HIV particle density, $\mathrm{NC}(\mathrm{CoN})$ and $\mathrm{NC}(\mathrm{N} 2)$ viral pellets were spun with wt pellets through the same sucrose density gradient. The results show that both Pr55 $5^{\text {gag }}$ and NC(N2) had peaks in fraction 6 with a density of $1.17 \mathrm{~g} / \mathrm{ml}$, consistent with wild-type HIV-1 particle density (Fig. 3). An $\mathrm{NC}(\mathrm{CoN})$ peak at fraction 7 with a density of approximately $1.19 \mathrm{~g} / \mathrm{ml}$ suggests that the encoded $\mathrm{NC}(\mathrm{CoN})$ was tightly packed when assembled into VLPs.

Mapping the SARS-CoV $\mathrm{N}$ domain is required for replacing the HIV-1 NC assembly function

Based on our observation that HIV-1 Gag containing SARS-CoV $\mathrm{N}$ coding sequences as NC substitutes was capable of VLP assembly, we tried to identify the SARS-
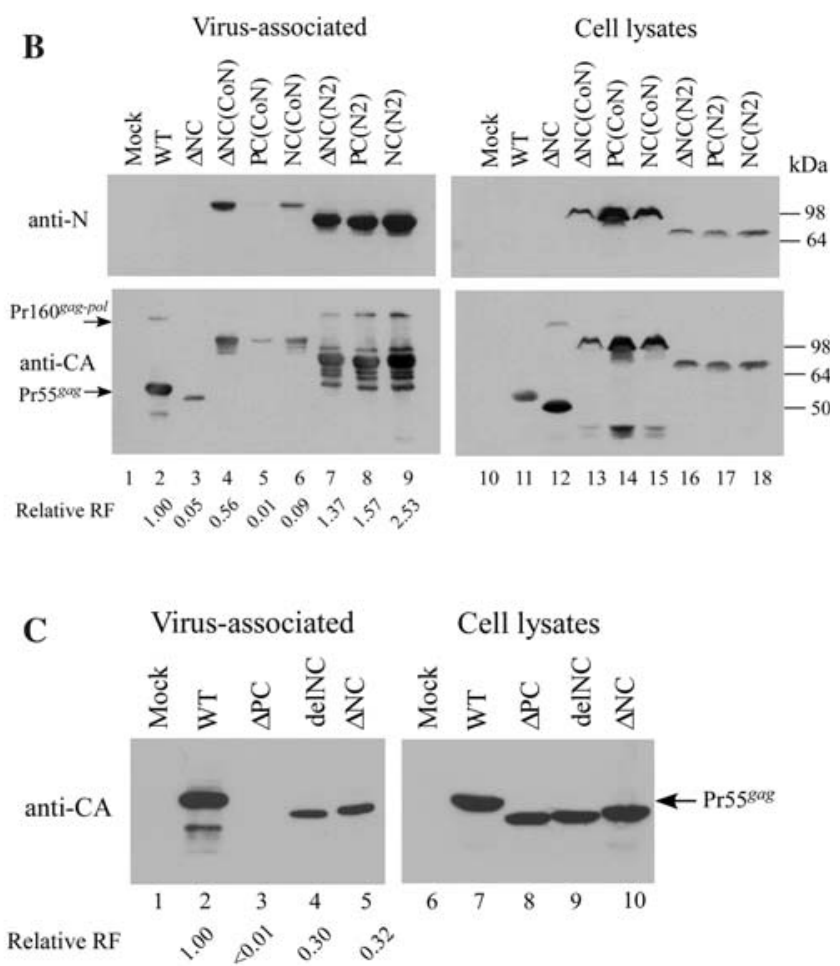

of chimeric proteins. 293T cells were transfected with $20 \mu \mathrm{g}$ plasmid DNA for each indicated construct. At $48 \mathrm{~h}$ post-transfection, cells and supernatant were collected for protein analysis as described in Materials and Methods. Cell samples corresponding to $4 \%$ of total cell lysates and supernatant samples corresponding to $50 \%$ of total recovered viral pellets were fractionated using 10\% SDS-PAGE. HIV-1 Gag or chimeric proteins were probed an anti-p24CA monoclonal antibody or with a monoclonal antibody directed against $\mathrm{N}$ (panel b, upper panels). Positions of wt HIV-1 Gag, Gag-Pol and molecular size markers are indicated. p24CA-associated proteins from medium or cell samples were quantified by scanning mutant and wt band densities from immunoblots. Ratios of p2 $4^{\text {gag }}$-associated protein levels in media to those in cells were determined for each construct and compared with wt release levels by dividing the release ratio for each mutant by the wt ratio in parallel experiments. Relative release factor $(\mathrm{RF})$ values are indicated

$\mathrm{CoV} \mathrm{N}$ regions responsible for conferring the assembly function. Toward this end we constructed a series of chimeras containing a variety of $\mathrm{N}$ coding regions as HIV-1 NC substitutes (Fig. 4a); the ability of each chimera to produce VLPs was determined by Western blot analysis. As shown in Fig. 4b, chimeras N1, N2 and N4 produced VLPs efficiently (lanes 4,5 , and 7). In contrast, the VLP quantities produced by chimeras N3, N5, N6, and N7 were smaller than those produced by the wt. Although VLP quantities produced by $\mathrm{NC}(\mathrm{N} 1)$ are markedly higher than those produced by $\triangle \mathrm{NC}(\mathrm{CoN}), \mathrm{NC}(\mathrm{N} 5)$ and $\mathrm{NC}(\mathrm{N} 6)$, the $\mathrm{NC}(\mathrm{N} 1)$ release efficiency (43\%) is relatively lower than the three's. This discrepancy may be due to different steady-state intracellular levels; relatively higher for $\mathrm{NC}(\mathrm{N} 1)$ but lower for $\triangle \mathrm{NC}(\mathrm{CoN}), \mathrm{NC}(\mathrm{N} 5)$ and $\mathrm{NC}(\mathrm{N} 6)$ 

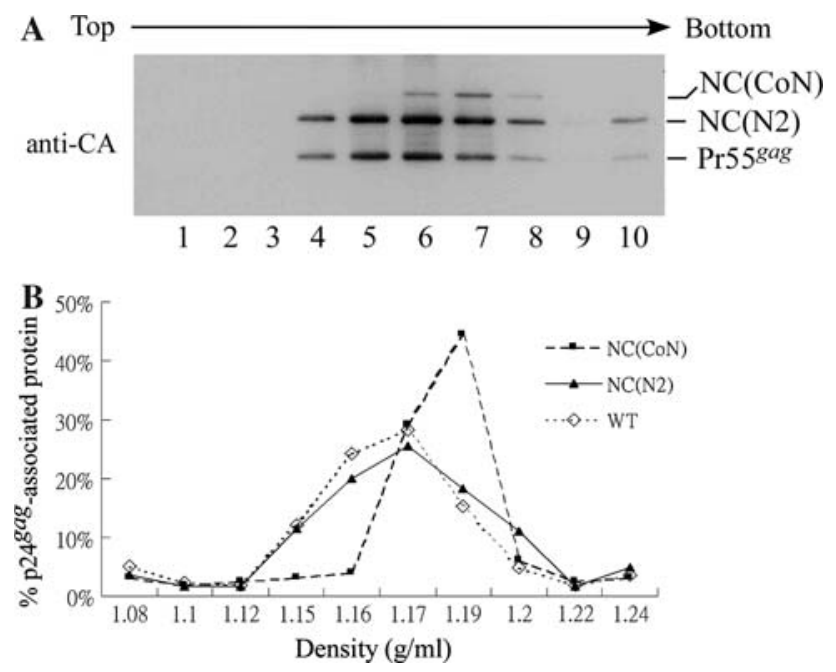

Fig. 3 Sucrose density gradient fractionation of wt and chimeric VLPs. (a) 293T cells were transfected with $20 \mu \mathrm{g}$ plasmid DNA from wt, $\mathrm{NC}(\mathrm{CoN})$, or $\mathrm{NC}(\mathrm{N} 2)$. At $48 \mathrm{~h}$ post-transfection, culture supernatant was collected, filtered, and pelleted through $20 \%$ sucrose cushions. Viral pellets were resuspended in PBS, pooled, and centrifuged through a $20-60 \%$ sucrose gradient for $16 \mathrm{~h}$. Ten equalamount fractions were collected from top to bottom. Fraction densities were measured and wt and chimeric proteins analyzed by Western immunoblotting with an anti-p24CA antibody. (b) p2 $4^{\text {gag }}$ associated wt and chimeric proteins were quantified via scanning densitometry. Band density units in each fraction were divided by total band density units of 10 fractions and multiplied by 100 . Percentages of $\mathrm{p} 24^{\mathrm{gag}}$-associated protein in each fraction were plotted against the fraction's sucrose density

(Fig. 4b, lanes 13, 15, 19 and 20). In addition, we cannot exclude the possibility of increased mutant VLP instability. Note that N1 was capable of efficient VLP production (Fig. 4b, lane 4) even though it could not effectively interact with the full-length $\mathrm{N}$ (Fig. 1b). These results suggest that the $\mathrm{N}$ sequence, which is capable of conferring chimeric VLP assembly, is located between residues 168 and 421 .

Based on evidence showing that the leucine-zipper motif is competent in replacing the HIV-NC assembly function, we built a construct designated $\triangle \mathrm{NC}(\mathrm{wtZiP})$ and containing a leucine-zipper motif sequence to serve as a control. We found that $\triangle \mathrm{NC}(\mathrm{wtZiP})$ produces VLPs at a level comparable to that of wt (Fig. 4c, lane 4 vs. lane 2). In contrast, $\triangle \mathrm{NC}(\mathrm{KZiP})$ (which contains a $\mathrm{NC}$ replacement consisting of a mutated leucine-zipper motif) was incapable of rescuing the $\triangle \mathrm{NC}$ assembly defect; VLP-associated chimeric proteins were barely detected (lane 5). Thus, the SARS-CoV N self-association domain is similar to leucinezipper motifs in conferring chimeric ability to direct VLP assembly by promoting protein-protein interactions.

Although SARS-CoV N is genetically unrelated to Gag, it is likely that $\mathrm{N}-\mathrm{Gag}$ cross-interaction contributes to chimeric VLP assembly. To test this possibility, we expressed SARS-CoV N with wt or individual chimeras containing full lengths, carboxyl-terminal halves, or amino-terminal halves of SARS-CoV N. Our results indicate that VLP-associated SARS-CoV N was undetectable when co-expressed with Gag or NC(N1) (Fig. 4d, lanes 3 and 5), suggesting that no significant $\mathrm{N}-\mathrm{Gag}$ interactions occurred and that interaction strength within the SARS$\mathrm{CoV} \mathrm{N}$ amino-terminal region is insufficient for $\mathrm{NC}(\mathrm{N} 1)$ to incorporate $\mathrm{N}$ into VLPs. Conversely, we readily detected VLP-associated N co-expressed with NC(N2) (lane 6). These results strongly suggest that SARS-CoV $\mathrm{N}$ incorporation into VLPs largely depends on intermolecular interactions within the carboxyl-terminal SARS-CoV N, which agrees with our GST pull-down assay results (Fig. 1b).

Our results also indicate that the N1 sequence as a NC substitute is capable of conferring efficient chimeric VLP assembly (Fig. $4 \mathrm{~b}, \mathrm{~d}$ ), suggesting that amino-terminal SARS-CoV N may also possess a potent self-interaction capacity. We therefore reasoned that $\mathrm{NC}(\mathrm{N} 1)$ could efficiently package GST-N1 via N1-N1 interactions if a strong $\mathrm{N} 1$ sequence self-association does exist. To test this idea, we co-expressed NC(N1) with GST-CoN, GST-N1, or GSTN2 and used isolated viral pellets for Western immunoblot analysis. Our results indicate that $\mathrm{NC}(\mathrm{N} 1)$ was incapable of packaging GST-CoN, GST-N1, or GST-N2that is, all of the GST fusion signals were barely detected in medium (Fig. 5a). In contrast, $\mathrm{NC}(\mathrm{N} 2)$ can efficiently package GST-N2 and GST-CoN (Fig. 5b, lanes 4 and 6), which is compatible with the proposal that the SARS-CoV $\mathrm{N}$ self-interaction domain is largely located in the carboxyl-terminal region. According to these data, any N1-N1 interaction strength is insignificant.

\section{Membrane flotation analysis of chimeric proteins}

Membrane association is required for HIV-1 Gag assembly and budding $[8,31]$. Results from a previous study show that HIV-1 NC facilitates Pr55 ${ }^{\text {gag }}$ membrane association [39]. Furthermore, most Gag mutants (either multimerization-defective or assembly-defective) demonstrate markedly reduced membrane binding capacities [9, 15, 23]. We performed membrane flotation experiments to test whether the replacement of HIV-1 NC by SARS-CoV N exerts any effect on membrane binding, and to determine if the assembly defect is correlated with reduced membranebinding capacity. Our results indicate that with the exception of $\triangle \mathrm{NC}(\mathrm{wtZiP})$, all of the chimeras expressed moderate reductions in membrane binding capacity (Fig. 6). $\quad \Delta \mathrm{NC}($ wtZiP) showed a membrane binding capacity comparable to wt and exhibited a positive correlation with VLP assembly competence.

Neither SARS-CoV N nor non-myristylated $\left(\mathrm{Myr}^{-}\right) \mathrm{Gag}$ were capable of efficient cell membrane association-that 

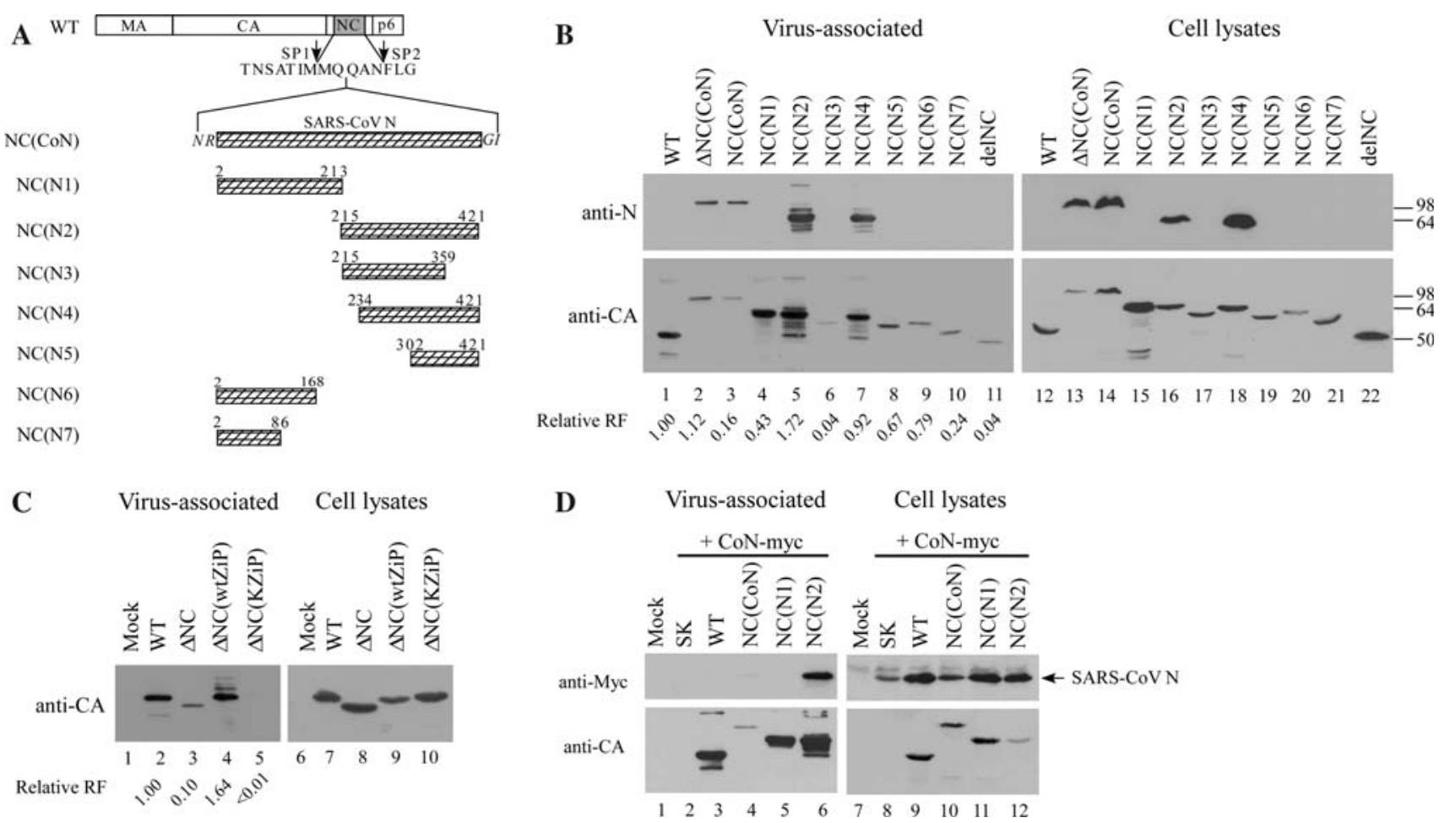

Fig. 4 Expression and assembly of chimeric protein containing a HIV-1 NC replacement consisting of SARS-CoV N coding sequences. (a) Schematic representation of chimeric constructs. Mature HIV-1 Gag protein domain and amino acid residues in SP1NC-SP2 junction area are indicated. PCR-amplified fragments containing various portions of SARS-CoV N coding sequences were inserted into the deleted $\mathrm{NC}$ regions. Numbers denote codon positions at inserted SARS-CoV N protein sequence boundaries. All constructs were expressed in HIVgptD25 (a HIV-1 PR-defective expression vector). Expression and release of wt Gag and chimeric proteins. $293 \mathrm{~T}$ cells were transfected with the indicated construct. $\triangle \mathrm{NC}$ (wtZiP) and $\Delta \mathrm{NC}(\mathrm{kZiP})$ contained HIV-1 NC replacements consisting of wild-type or a mutated version of a leucine zipper domain, respectively. At $48-72 \mathrm{~h}$ post-transfection, supernatant and cells

is, less than $10 \%$ of total expressed protein was membranebound (Fig. 6b). However, the assembly-competent $\mathrm{NC}(\mathrm{N} 2)$ and $\mathrm{NC}(\mathrm{N} 1)$ and the assembly-defective $\Delta \mathrm{NC}$ and $\mathrm{NC}(\mathrm{N} 3)$ displayed similar levels of membrane-binding capacity (50-60\% of total membrane-associated protein). Even $\triangle \mathrm{NC}(\mathrm{KZiP})$, which is severely defective in VLP assembly, had an encoded protein membrane-associated level of over $40 \%$. The results suggest that $\mathrm{NC}$ is not required for efficient Gag membrane association.

\section{Discussion}

Results from several recent SARS-CoV N protein characterization studies suggest the presence of a putative selfinteraction domain within the carboxyl-terminal region [10, $26,42,43,51]$. These studies involve in vitro assays using purified recombinant $\mathrm{N}$ proteins, co-immunoprecipitation,

were collected, prepared, and subjected to SDS-10\% PAGE. HIV-1 Gag or chimeric proteins were detected by Western immunoblotting using monoclonal antibodies against SARS-CoV N or against HIV-1 p24CA. Positions of molecular size markers are indicated. Relative VLP release efficiency for each mutant was determined as described in the Fig. 2 caption; relative release factor values are indicated. (b) Expression and incorporation of SARS-CoV N protein into chimeric VLPs. 293T cells were co-transfected with $10 \mu \mathrm{g}$ CoN-myc plus $10 \mu \mathrm{g}$ pBlueScript SK or indicated construct. At $48-72 \mathrm{~h}$ posttransfection, cells and supernatant were collected and subjected to Western immunoblotting. SARS-CoV N protein was probed with an anti-Myc antibody and wt Gag or chimeric proteins were detected with an anti-p24CA antibody

or hybrid yeast systems. For the present study we established a chimeric VLP assembly process to analyze SARS$\mathrm{CoV} \mathrm{N}$ self-interaction capacity. Our evidence-that chimeras containing the SARS-CoV $\mathrm{N}$ protein coding sequence as a substitute for HIV-1 NC are capable of producing substantial amounts of VLPs—supports the idea that retroviral gag is capable of tolerating major mutations $[48,49,54]$. The inability of the $\mathrm{PC}(\mathrm{CoN})$ chimera to produce VLPs cannot be explained solely by an assembly limitation of extra-large proteins-as is the case with $\Delta \mathrm{NC}(\mathrm{CoN})$, which contains the same full-length $\mathrm{N}$ yet still produces significant amounts of VLPs.

One possible explanation for this discrepancy is that $\Delta \mathrm{NC}(\mathrm{CoN})$ retains the $\mathrm{N}$-terminal region of the I domain, while $\mathrm{PC}(\mathrm{CoN})$ lacks the entire I domain and parts of SP1. Researchers who have studied the roles of I and SP1 domains in virus assembly have observed that some mutations in either one disrupt Gag multimerization, thus 


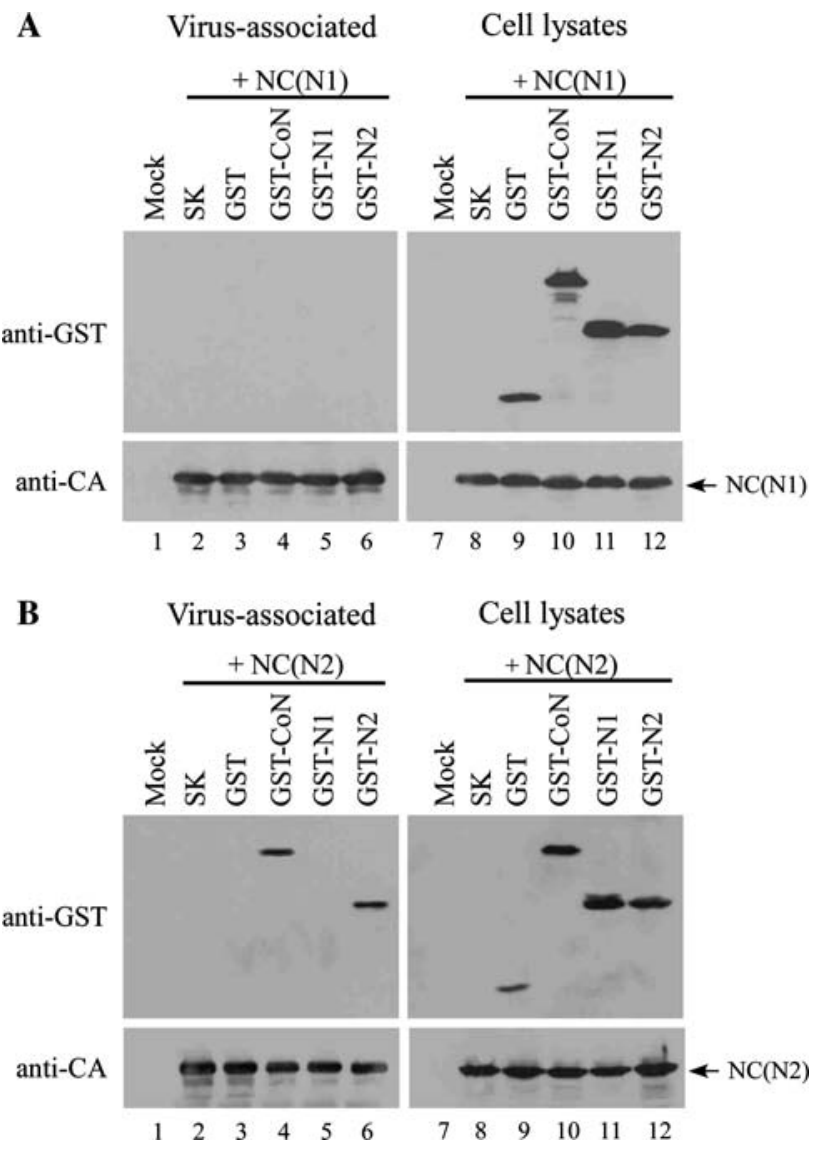

Fig. 5 Incorporation of GST fusion proteins into virus-like particles. $293 \mathrm{~T}$ cells were co-transfected with $10 \mu \mathrm{g}$ of $\mathrm{NC}(\mathrm{N} 1)$ (panel a) or $\mathrm{NC}(\mathrm{N} 2)$ (panel b) plus $10 \mu \mathrm{g}$ pBlueScript SK or indicated construct. At $48-72 \mathrm{~h}$ post-transfection, supernatant and cells were collected, prepared, and subjected to SDS-10\% PAGE. HIV-1 Gag or chimeric proteins were detected by Western immunoblotting using a monoclonal antibody against HIV-1 p24CA. GST or GST fusions were probed with an anti-GST monoclonal antibody

reducing VLP production $[9,15,23,28,40,54]$. However, we found that PC(N2) produced VLPs at an efficiency level comparable to that of wt (Fig. $2 \mathrm{~b}$, lane 8 vs. lane 2). Furthermore, VLPs produced by $\mathrm{NC}(\mathrm{N} 2)$ possess a particle density similar to that of wt HIV-1, indicating that chimeric proteins are packed in a manner similar to that of wt. Combined, these results suggest that SARS-CoV N residues 215-421 confer a potent self-interaction capacity capable of rescuing the assembly defects of NC-deleted mutants. Although the transformation of a severe assembly-defective $\triangle \mathrm{PC}$ into an assembly-competent $\mathrm{PC}(\mathrm{N} 2)$ provides compelling evidence that SARS-CoV N possesses a self-interaction domain capable of replacing the HIV-1 $\mathrm{NC}$ assembly function, we chose the delNC instead of $\triangle \mathrm{PC}$ as a backbone for our SARS-CoV N fragment analysis. Our main reason was that all of the $\triangle \mathrm{PC}$-derived constructs lacked SP1, and therefore had the potential to disrupt an accurate assessment of SARS-CV N sequences involved in VLP assembly.
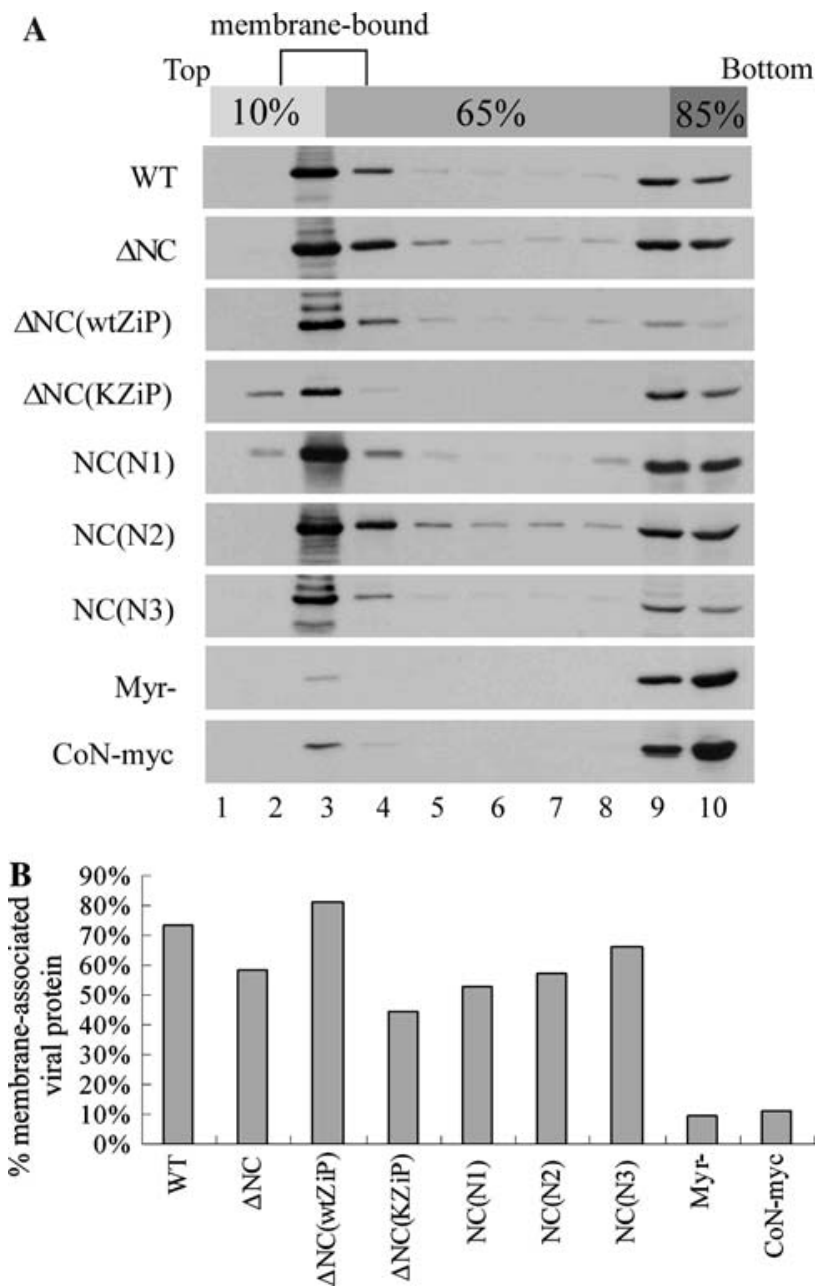

Fig. 6 Membrane flotation analysis of chimeric proteins. 293T cells were transfected with wt or indicated expression construct. (a) Membrane binding-defective Gag (nonmyristylated, $\mathrm{Myr}^{-}$) served as control. Cells were harvested, homogenized, and subjected to equilibrium flotation centrifugation analysis 2 days post-transfection. Ten fractions were collected from top to bottom. Fraction aliquots were resolved using SDS-PAGE (10\%) and probed with a monoclonal antibody directed against HIV-1 CA or the Myc tag. During ultracentrifugation, membrane-bound Gag proteins floated to the $10-65 \%$ sucrose interface and became enriched in fraction 2. (b) Band densities in fractions 2, 3 and 4 were divided by total band densities of fractions $1-10$ and multiplied by 100 to obtain percentages of membrane-bound protein for each construct

According to previous in vitro biochemical and biophysical studies, a variety of recombinant SARS-CoV N proteins consisting of the carboxyl-terminal residues 213 422 [42], 283-422 [25], 284-422 [51], 169-422 [43], or 248-365 [10] are capable of self-associating as either dimers or multimers. This suggests that $\mathrm{N}$ residues 248 365 may constitute a minimum required sequence for $\mathrm{N}$ self-association. Both of our inserted $\mathrm{NC}(\mathrm{N} 2)$ and $\mathrm{NC}(\mathrm{N} 4)$ sequences containing residues 248-365 were capable of driving efficient VLP production, perhaps by promoting chimeric protein multimerization via the inserted sequence. 
The inability of NC(N3) to efficiently direct VLP assembly may be due in part to the exclusion of residues 360-365 in the inserted $\mathrm{N}$ sequence. According to one previous report, SARS-CoV N residues 343-402 are necessary and sufficient for oligomerizing the carboxyl-terminal region [26]. However, we have consistently observed that $\mathrm{NC}(\mathrm{N} 5)$ cannot direct VLP assembly as efficiently as $\mathrm{NC}(\mathrm{N} 2)$ or $\mathrm{NC}(\mathrm{N} 4)$, suggesting that the region between residues 234 and 302 is important for driving efficient VLP assembly and release.

Results from a crystal structural study of the SARS-CoV $\mathrm{N}$ carboxyl-terminal region imply extensive $\mathrm{N}-\mathrm{N}$ interaction involving residues 270-370 [52]. Accordingly, the ability of chimeras containing a variety of $\mathrm{N}$ sequences to act as a HIV-1 NC replacement for directing VLP assembly is compatible with studies indicating that inserted $\mathrm{N}$ sequences can promote efficient VLP assembly, providing that such sequences retain most $\mathrm{N}$ residues between 270 and 370 .

However, it is unlikely that the ability of an inserted $\mathrm{N}$ sequence to confer chimeric VLP assembly reflects its capacity for in vitro self-association. $\mathrm{NC}(\mathrm{N} 1)$ (containing $\mathrm{N}$ residues 2-213) is capable of producing substantial amounts of VLPs (Fig. 4b), despite being defective in packaging the co-expressed $\mathrm{N}$ protein (Fig. 4d). Also note that GST-N1 was incapable of efficiently pulling down the $\mathrm{N}$ protein (Fig. 1b) or of being packaged into $\mathrm{NC}(\mathrm{N} 1)$ VLPs (Fig. 5). One possible explanation for this discrepancy is that the $\mathrm{N} 1$ sequence may contain a self-association domain that fails to confer sufficient interaction strength for self-association or associating with a full-length $\mathrm{N}$. It has previously been demonstrated that a serine/argininerich motif between $\mathrm{N}$ residues 184 and 196 is crucial for $\mathrm{N}$ protein self-multimerization [16]. Since CA-SP1 is largely responsible for driving Gag or chimeric protein self-association, protein sequences with small self-interaction capacities may be sufficient for restoring delNC VLP assembly to wt levels when substituted for NC. If true, it is likely that the $\mathrm{N}$ serine/arginine-rich motif in the context of NC(N1) makes a significant contribution to VLP assembly. In agreement with this hypothesis, $\mathrm{NC}(\mathrm{N} 6)$ and $\mathrm{NC}(\mathrm{N} 7)$ (both lacking residues 184-196) were found to trigger moderate-to-marked decreases in VLP production compared to $\mathrm{NC}(\mathrm{N} 1)$, suggesting that even though the N selfinteraction domain primarily resides in the carboxylterminal region, part of the amino-terminal $\mathrm{N}$ may be involved in $\mathrm{N}$ self-association.

Inserting the mutated leucine-zipper domain into the HIV-1 NC deleted region abolished VLP production, suggesting that the inserted sequence may have impaired Gag-Gag interaction to the extent that proper Gag multimerization could not proceed, even though a major CA dimerization domain was retained in the chimera. The
$\mathrm{N}$-containing chimeras were not equally effective in rescuing the NC assembly defect. However, the inserted SARS-CoV N sequences did not trigger further restrictions on Gag-Gag interaction-that is, low but detectable amounts of VLPs were observed in most of the chimeras.

Acknowledgments We thank C.-Y. Chang and Y.-P. Li for reagents and technical assistance, and E. Barklis for plasmids coding the leucine-zipper domain. This work was supported by grants VGH94314 from the Taipei Veterans General Hospital and NSC94-2320-B010-035 from the National Science Council, Taiwan, Republic of China.

\section{References}

1. Accola MA, Strack B, Gottlinger HG (2000) Efficient particle production by minimal Gag constructs which retain the carboxyterminal domain of human immunodeficiency virus type 1 capsidp2 and a late assembly domain. J Virol 74(12):5395-5402

2. Baudoux P, Carrat C, Besnardeau L, Charley B, Laude H (1998) Coronavirus pseudoparticles formed with recombinant $\mathrm{M}$ and $\mathrm{E}$ proteins induce alpha interferon synthesis by leukocytes. J Virol 72(11):8636-8643

3. Bennett RP, Nelle TD, Wills JW (1993) Functional chimeras of the Rous sarcoma virus and human immunodeficiency virus gag proteins. J Virol 67(11):6487-6498

4. Berkowitz RD, Luban J, Goff SP (1993) Specific binding of human immunodeficiency virus type 1 gag polyprotein and nucleocapsid protein to viral RNAs detected by RNA mobility shift assays. J Virol 67(12):7190-7200

5. Berkowitz RD, Ohagen A, Hoglund S, Goff SP (1995) Retroviral nucleocapsid domains mediate the specific recognition of genomic viral RNAs by chimeric Gag polyproteins during RNA packaging in vivo. J Virol 69(10):6445-6456

6. Bos ECW, Luytjes W, Meulen HVD, Koerten HK, Spaan WJM (1996) The production of recombinant infectious DI-particles of a murine coronavirus in the absence of helper virus. Virology 218(1):52-60

7. Bowzard JB, Bennett RP, Krishna NK, Ernst SM, Rein A, Wills JW (1998) Importance of basic residues in the nucleocapsid sequence for retrovirus Gag assembly and complementation rescue. J Virol 72(11):9034-9044

8. Bryant M, Ratner L (1990) Myristoylation-dependent replication and assembly of human immunodeficiency virus 1 . Proc Natl Acad Sci USA 87(2):523-527

9. Burniston MT, Cimarelli A, Colgan J, Curtis SP, Luban J (1999) Human immunodeficiency virus type 1 Gag polyprotein multimerization requires the nucleocapsid domain and RNA and is promoted by the capsid-dimer interface and the basic region of matrix protein. J Virol 73(10):8527-8540

10. Chang C-K, Sue S-C, Yu T-H, Hsieh C-M, Tsai C-K, Chiang Y-C, Lee S-J, Hsiao H-H, Wu W-J, Chang W-L, Lin C-H, Huang T-H (2006) Modular organization of SARS coronavirus nucleocapsid protein. J Biomed Sci 13(1):59-72

11. Cortes P, Weis-Garcia F, Misulovin Z, Nussenzweig A, Lai J-S, Li G, Nussenzweig M, Baltimore D (1996) In vitro V(D)J recombination: signal joint formation. Proc Natl Acad Sci USA 93(24):14008-14013

12. de Haan CA, Kuo L, Masters PS, Vennema H, Rottier PJ (1998) Coronavirus particle assembly: primary structure requirements of the membrane protein. J Virol 72(8):6838-6850

13. Drosten C, Gunther S, Preiser W, van der Werf S, Brodt H-R, Becker S, Rabenau H, Panning M, Kolesnikova L, Fouchier 
RAM, Berger A, Burguiere A-M, Cinatl J, Eickmann M, Escriou N, Grywna K, Kramme S, Manuguerra J-C, Muller S, Rickerts V, Sturmer M, Vieth S, Klenk H-D, Osterhaus ADME, Schmitz H, Doerr HW (2003) Identification of a novel coronavirus in patients with severe acute respiratory syndrome. $\mathrm{N}$ Engl J Med 348(20):1967-1976

14. Gheysen D, Jacobs E, Foresta FD, Thiriart C, Francotte M, Thines D, Wilde MD (1989) Assembly and release of HIV-1 precursor Pr55gag virus-like particles from recombinant baculovirus-infected insect cells. Cell 59(1):103-112

15. Guo X, Roldan A, Hu J, Wainberg MA, Liang C (2005) Mutation of the SP1 sequence impairs both multimerization and membrane-binding activities of human immunodeficiency virus type 1 Gag. J Virol 79(3):1803-1812

16. He R, Dobie F, Ballantine M, Leeson A, Li Y, Bastien N, Cutts T, Andonov A, Cao J, Booth TF (2004) Analysis of multimerization of the SARS coronavirus nucleocapsid protein. Biochem Biophys Res Commun 316(2):476-483

17. Hsieh P-K, Chang SC, Huang C-C, Lee T-T, Hsiao C-W, Kou Y-H, Chen IY, Chang C-K, Huang T-H, Chang M-F (2005) Assembly of severe acute respiratory syndrome coronavirus RNA packaging signal into virus-like particles is nucleocapsid dependent. J Virol 79(22):13848-13855

18. Huang Q, Yu L, Petros AM, Gunasekera A, Liu Z, Xu N, Hajduk P, Mack J, Fesik SW, Olejniczak ET (2004) Structure of the N-terminal RNA-binding domain of the SARS CoV nucleocapsid protein. Biochemistry 43(20):6059-6063

19. Huang Y, Yang ZY, Kong WP, Nabel GJ (2004) Generation of synthetic severe acute respiratory syndrome coronavirus pseudoparticles: implications for assembly and vaccine production. J Virol 78(22):12557-12565

20. Johnson MC, Scobie HM, Ma YM, Vogt VM (2002) Nucleic acid-independent retrovirus assembly can be driven by dimerization. J Virol 76(22):11177-11185

21. Ksiazek TG, Erdman D, Goldsmith CS, Zaki SR, Peret T, Emery S, Tong S, Urbani C, Comer JA, Lim W, Rollin PE, Dowell SF, Ling A-E, Humphrey CD, Shieh W-J, Guarner J, Paddock CD, Rota P, Fields B, DeRisi J, Yang J-Y, Cox N, Hughes JM, LeDuc JW, Bellini WJ, Anderson LJ, SARS·Working Group (2003) A novel coronavirus associated with severe acute respiratory syndrome. N Engl J Med 348(20):1953-1966

22. Lai MM, Cavanagh D (1997) The molecular biology of coronaviruses. Adv Virus Res 48:1-100

23. Liang C, Hu J, Russell RS, Roldan A, Kleiman L, Wainberg MA (2002) Characterization of a putative alpha-helix across the capsid-SP1 boundary that is critical for the multimerization of human immunodeficiency virus type 1 gag. J Virol 76(22):11729-11737

24. Loriaux MM, Rehfuss RP, Brennan RG, Goodman RH (1993) Engineered leucine zippers show that hemiphosphorylated CREB complexes are transcriptionally active. Proc Natl Acad Sci USA 90(19):9046-9050

25. Luo H, Ye F, Chen K, Shen X, Jiang H (2005) SR-rich motif plays a pivotal role in recombinant SARS coronavirus nucleocapsid protein multimerization. Biochemistry 44:15351-15358

26. Luo H, Chen J, Chen K, Shen X, Jiang H (2006) Carboxyl terminus of severe acute respiratory syndrome coronavirus nucleocapsid protein: self-association analysis and nucleic acid binding characterization. Biochemistry 45(39):11827-11835

27. Marra MA, Jones SJM, Astell CR, Holt RA, Brooks-Wilson A, Butterfield YSN, Khattra J, Asano JK, Barber SA, Chan SY, Cloutier A, Coughlin SM, Freeman D, Girn N, Griffith OL, Leach SR, Mayo M, McDonald H, Montgomery SB, Pandoh PK, Petrescu AS, Robertson AG, Schein JE, Siddiqui A, Smailus DE, Stott JM, Yang GS, Plummer F, Andonov A, Artsob H, Bastien N, Bernard K, Booth TF, Bowness D, Czub M, Drebot M,
Fernando L, Flick R, Garbutt M, Gray M, Grolla A, Jones S, Feldmann H, Meyers A, Kabani A, Li Y, Normand S, Stroher U, Tipples GA, Tyler S, Vogrig R, Ward D, Watson B, Brunham RC, Krajden M, Petric M, Skowronski DM, Upton C, Roper RL (2003) The genome sequence of the SARS-associated coronavirus. Science 300(5624):1399-1404

28. Morikawa Y, Hockley DJ, Nermut MV, Jones IM (2000) Roles of matrix, p2, and N-terminal myristoylation in human immunodeficiency virus type $1 \mathrm{Gag}$ assembly. J Virol 74(1):16-23

29. Narayanan K, Maeda A, Maeda J, Makino S (2000) Characterization of the coronavirus $M$ protein and nucleocapsid interaction in infected cells. J Virol 74(17):8127-8134

30. Narayanan K, Kim KH, Makino S (2003) Characterization of N protein self-association in coronavirus ribonucleoprotein complexes. Virus Res 98(2):131-140

31. Pal R, Reitz MS Jr, Tschanchler E, Gallo RC, Sarngadharan MG, Veronese FDM (1990) Myristylation of gag proteins of HIV-1 plays an important role in virus assembly. AIDS Res Hum Retroviruses 6:721-730

32. Poon DT, Wu J, Aldovini A (1996) Charged amino acid residues of human immunodeficiency virus type 1 nucleocapsid $\mathrm{p} 7$ protein involved in RNA packaging and infectivity. J Virol 70(10):66076616

33. Poon DT, Li G, Aldovini A (1998) Nucleocapsid and matrix protein contributions to selective human immunodeficiency virus type 1 genomic RNA packaging. J Virol 72(3):1983-1993

34. Ratner L, Haseltine W, Patarca R, Livak KJ, Starcich B, Josephs SF, Doran ER, Rafalski JA, Whitehorn EA, Baumeister K et al (1985) Complete nucleotide sequence of the AIDS virus, HTLVIII. Nature 313(6000):277-284

35. Risco C, Anton IM, Enjuanes L, Carrascosa JL (1996) The transmissible gastroenteritis coronavirus contains a spherical core shell consisting of M and N proteins. J Virol 70(7):4773-4777

36. Rota PA, Oberste MS, Monroe SS, Nix WA, Campagnoli R, Icenogle JP, Penaranda S, Bankamp B, Maher K, Chen MH, Tong S, Tamin A, Lowe L, Frace M, DeRisi JL, Chen Q, Wang D, Erdman DD, Peret TC, Burns C, Ksiazek TG, Rollin PE, Sanchez A, Liffick S, Holloway B, Limor J, McCaustland K, Olsen-Rasmussen M, Fouchier R, Gunther S, Osterhaus AD, Drosten C, Pallansch MA, Anderson LJ, Bellini WJ (2003) Characterization of a novel coronavirus associated with severe acute respiratory syndrome. Science 300(5624):1394-1399

37. Salanueva IJ, Carrascosa JL, Risco C (1999) Structural maturation of the transmissible gastroenteritis coronavirus. J Virol 73(10):7952-7964

38. Sambrook J, Russell DW (2001) Molecular cloning: a laboratory manual, 3rd edn. Cold Spring Harbor Laboratory Press, Cold Spring Harbor

39. Sandefur S, Varthakavi V, Spearman P (1998) The I domain is required for efficient plasma membrane binding of human immunodeficiency virus type 1 Pr55Gag. J Virol 72(4):27232732

40. Sandefur S, Smith RM, Varthakavi V, Spearman P (2000) Mapping and characterization of the N-terminal I domain of human immunodeficiency virus type 1 Pr55Gag. J Virol 74(16):7238-7249

41. Surjit M, Lal SK (2008) The SARS-CoV nucleocapsid protein: a protein with multifarious activities. Infect Genet Evol 8(4):397405

42. Surjit M, Liu B, Kumar P, Chow VT, Lal SK (2004) The nucleocapsid protein of the SARS coronavirus is capable of selfassociation through a C-terminal 209 amino acid interaction domain. Biochem Biophys Res Commun 317(4):1030-1036

43. Tang TK, Wu MP, Chen ST, Hou MH, Hong MH, Pan FM, Yu $\mathrm{HM}$, Chen JH, Yao CW, Wang AH (2005) Biochemical and immunological studies of nucleocapsid proteins of severe acute 
respiratory syndrome and 229E human coronaviruses. Proteomics 5(4):925-937

44. Vennema H, Godeke GJ, Rossen JW, Voorhout WF, Horzinek MC, Opstelten DJ, Rottier PJ (1996) Nucleocapsid-independent assembly of coronavirus-like particles by co-expression of viral envelope protein genes. EMBO J 16(8):2020-2028

45. Wang CT, Barklis E (1993) Assembly, processing, and infectivity of human immunodeficiency virus type 1 gag mutants. J Virol 67(7):4264-4273

46. Wang C-T, Lai H-Y, Li J-J (1998) Analysis of minimal human immunodeficiency virus type $1 \mathrm{Gag}$ coding sequences capable of virus-like particle assembly and release. J Virol 72(10):7950 7959

47. Wang C-T, Chou Y-C, Chiang C-C (2000) Assembly and processing of human immunodeficiency virus Gag mutants containing a partial replacement of the matrix domain by the viral protease domain. J Virol 74(7):3418-3422

48. Weldon RA Jr, Wills JW (1993) Characterization of a small (25kilodalton) derivative of the Rous sarcoma virus Gag protein competent for particle release. J Virol 67(9):5550-5561
49. Weldon RA Jr, Erdie CR, Oliver MG, Wills JW (1990) Incorporation of chimeric gag protein into retroviral particles. J Virol 64(9):4169-4179

50. World HO (2004) World health report 2004—changing history. http://www.who.int/whr/2004/chapter5/en/

51. Yu IM, Gustafson CL, Diao J, Burgner JW 2nd, Li Z, Zhang J, Chen J (2005) Recombinant severe acute respiratory syndrome (SARS) coronavirus nucleocapsid protein forms a dimer through its C-terminal domain. J Biol Chem 280(24):23280-23286

52. Yu IM, Oldham ML, Zhang J, Chen J (2006) Crystal structure of the severe acute respiratory syndrome (SARS) coronavirus nucleocapsid protein dimerization domain reveals evolutionary linkage between corona- and arteriviridae. J Biol Chem 281(25):17134-17139

53. Zhang Y, Barklis E (1997) Effects of nucleocapsid mutations on human immunodeficiency virus assembly and RNA encapsidation. J Virol 71(9):6765-6776

54. Zhang Y, Qian H, Love Z, Barklis E (1998) Analysis of the assembly function of the human immunodeficiency virus type 1 Gag protein nucleocapsid domain. J Virol 72(3):1782-1789 